pests ${ }^{15-17}$, or even for the release of natural enemies that have been artificially selected for resistance to specific pesticides ${ }^{18}$.

The second possible explanation lies in the dynamics of prey/predator associations. The essentials of Tabashnik's detailed numerical simulations ${ }^{11}$ can be appreciated from the qualitative arguments given above. Suppose application of a pesticide kills a large fraction of both prey and predators in the treated region: for the surviving prey, life is now relatively good (relatively free from predators), and the population is likely to increase rapidly exhibiting overcompensating density dependence; for the surviving predators, life is relatively bad (food is harder to find), and their population will tend to recover slowly - exhibiting undercompensating density dependence. But we have just seen how the interplay between selection and gene flow is such that overcompensation tends to speed the evolution of resistance, and undercompensation to retard it. Thus, on dynamical grounds alone, we may expect that pests evolve resistance faster than do their natural enemies.

Although many well-understood resistance systems involve one locus with two alleles, with heterozygotes of intermediate fitness, other systems are possible and can pose different kinds of management questions. For instance, $R S$ heterozygotes may be the most fit in the presence of the pesticide. Resistance of the Norway rat to warfarin is the clearest example, and anyone who is tired of presenting sickle-cell anaemia to classes as the canonical example of heterzygous advantage may care to note the fitness ratios of the Norway rat in Britain in the absence of warfarin are $w_{R R}: w_{R S}: w_{S S}=0.46: 0.77$ $: 1.00$, whereas in the presence of the poison they are $0.37: 1.00: 0.68$ (J. Greaves, MAFF, South Tolworth, Surrey). But there may also be examples of heterozygous superiority among insects, as in the resistance of the spotted root-maggot Euxesta notada to DDT or dieldrin ${ }^{19}$. Heterozygous superiority of this kind undercuts the simple analyses presented above ${ }^{20}$.

Resistance systems that are sufficiently polygenic to warrant treatment by quantitative genetics, rather than being inherited in discrete, diallelic fashion, present interesting possibilities (S. Via, University of Iowa). For example, resistance to two different pesticides can be negatively correlated, enabling the evolution of resistance to be retarded by alternating the pesticides. Conversely, if the correlation were to be positive it would result in swift appearance of resistance to the second pesticide, following sustained use of the first. $M$. Uyenoyama (Duke University) discussed possible complications arising from modifier genes in two-locus systems of resistance. One possibility is the removal of fitness disadvantages in resistant genotypes in the absence of pesticide usage, if ever the resistance gene attained high frequency; if this happened, one could not

\title{
Most ancient aggregation of serpents
}

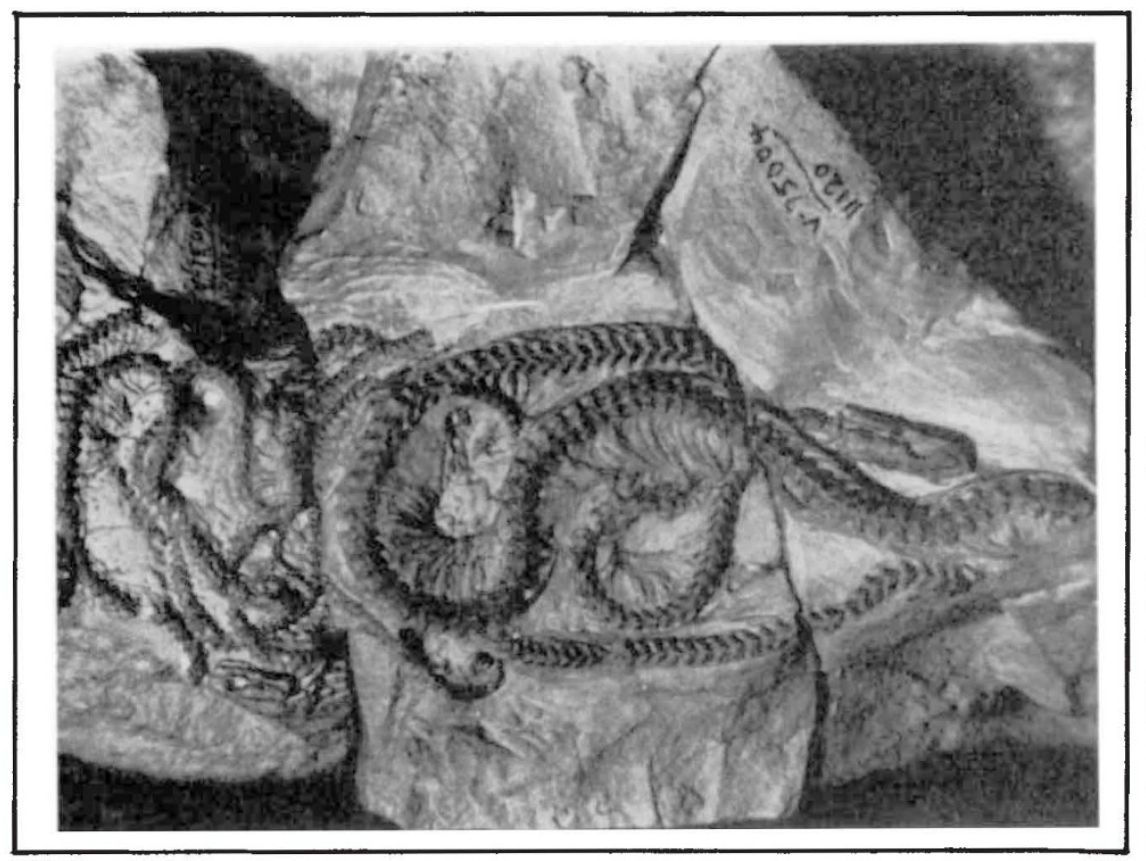

THE oldest record of serpent aggregation is preserved in this rare fossil from the Oligocene White River Formation of Converse County, Wyoming. The assemblage consists of three virtually complete 32 million-year-old snakes passively coiled in lifelike positions. As described by Brent $\mathrm{H}$. Breithaupt and David Duvall of the University of Wyoming, USA (in a paper in the press in Rates of Behavioral Evolution, ed. Bocout, A.J., Plenum, New York; and in a manuscript under review) the largest snake (435 $\mathrm{mm}$ long) belongs to the genus Ogmophis, whereas the smaller pair belong to the genus Calamagras. Both genera are common middle Tertiary forms of the subfamily Erycinae, family Boidea, and are distantly related to the North American rubber boa (Charina) and rosey boa (Lichanura). This specimen represents the most complete material known for these two fossil genera and is the first serpent cranial material recovered from Oligocene strata of North America. It is also the only known specimen in the world in which more than one complete snake is preserved and it suggests that aggregation, a behaviour that is extremely common in living snakes, was already a feature of serpent social behaviour at least $\mathbf{3 2}$ million years ago.

rely on 'back-selection' to purge resistance genes from the population after application of the pesticide was discontinued.

If dosage levels, migration, refugia, natural enemies and other factors are to be managed so as to slow down the evolution of pesticide resistance, coordination of efforts over large regions will be required. Some crops lend themselves to this, and some do not. Often the best interests of individuals will differ from those of groups, leading to problems that are social and

1. Crow, J.F. \& Kimura, M. An Introduction to the Theory of Population Genetics (Harper and Row, New York, 1970). 2. Mayr, E. Animal Species and Evolution (Harvard University Press, 1963)

3. Endler, J.A. Geographic Variation, Speciation and Clines (Princeton University Press, 1977).

4. Comins, H.N. J. theor. Biol. 64, 177 (1977)

5. Comins, H.N. J. theor Biol. 77, 171 (1979).

6. Georghiou, G.P. \& Taylor, C.E. J. econ. Ent. 70, 319 (1977)

7. Taylor, C.E. \& Georghiou, G.P. Environ. Ent. 11, 746 (1982)

8. Hassell, M.P., Lawton, J.H. \& May, R.M. J. anim. Ecol. 45, 471 (1976).

9. Stubbs, M. J. anim. Ecol. 46, 677 (1977)

10. Bellows, T.S. J. anim. Ecol. 50, 139 (1981).

1. Tabashnik, B.E. \& Croft, B.A. Environ. Ent. 11, 1137 (1982). political rather than purely biological. Beyond this, even with good biological understanding and coherent planning of group actions, I think it will often be that different sectors - pesticide manufacturers, farmers, and the planners responsible for feeding people - have different aims, stemming from different rates of discounting the future and the absence of a truly common coinage. Population biology can make these tensions clearer, but it cannot resolve them.

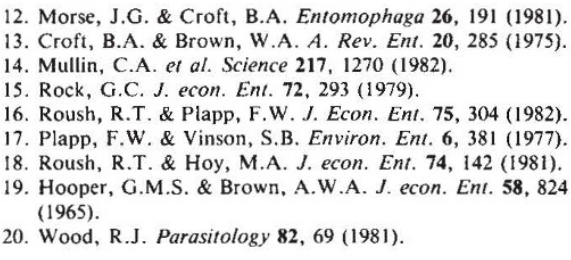

12. Morse, J.G. \& Croft, B.A. Entomophaga 26, 191 (1981). 13. Croft, B.A. \& Brown, W.A. A. Rev. Ent. 20, 285 (1975). 14. Mullin, C.A. et al. Science 217, 1270 (1982) 15. Rock, G.C. J. econ. Ent. 72, 293 (1979)

16. Roush, R.T. \& Plapp, F.W. J. Econ. Ent. 75, 304 (1982). 17. Plapp, F.W. \& Vinson, S. B. Environ. Ent. 6, 381 (1977). 18. Roush, R.T. \& Hoy, M.A.J. econ. Ent. 74, 142 (1981).

19. Hooper, G.M.S. \& Brown, A.W.A. J. econ. Ent. 58, 824 (1965).

20. Wood, R.J. Parasitology 82, 69 (1981).

Robert M. May is Class of 1877 Professor of Zoology, Princeton University, New Jersey 08544, USA. 